\title{
Spectral Analysis of EEG Signals during Working Memory Tasks
}

\author{
S. N. A. Naushad and W. Mansor
}

To Link this Article: http://dx.doi.org/10.6007/IJARBSS/v11-i12/12006

DOI:10.6007/IJARBSS/v11-i12/12006

Received: 06 October 2021, Revised: 09 November 2021, Accepted: 25 November 2021

Published Online: 19 December 2021

In-Text Citation: (Naushad \& Mansor, 2021)

To Cite this Article: Naushad, S. N. A., \& Mansor, W. (2021). Spectral Analysis of EEG Signals during Working Memory Tasks. International Journal of Academic Research in Business and Social Sciences, 11(12), 26542662.

Copyright: () 2021 The Author(s)

Published by Human Resource Management Academic Research Society (www.hrmars.com)

This article is published under the Creative Commons Attribution (CC BY 4.0) license. Anyone may reproduce, distribute, translate and create derivative works of this article (for both commercial and non0-commercial purposes), subject to full attribution to the original publication and authors. The full terms of this license may be seen at: http://creativecommons.org/licences/by/4.0/legalcode

Vol. 11, No. 12, 2021, Pg. 2654- 2662

Full Terms \& Conditions of access and use can be found at http://hrmars.com/index.php/pages/detail/publication-ethics 


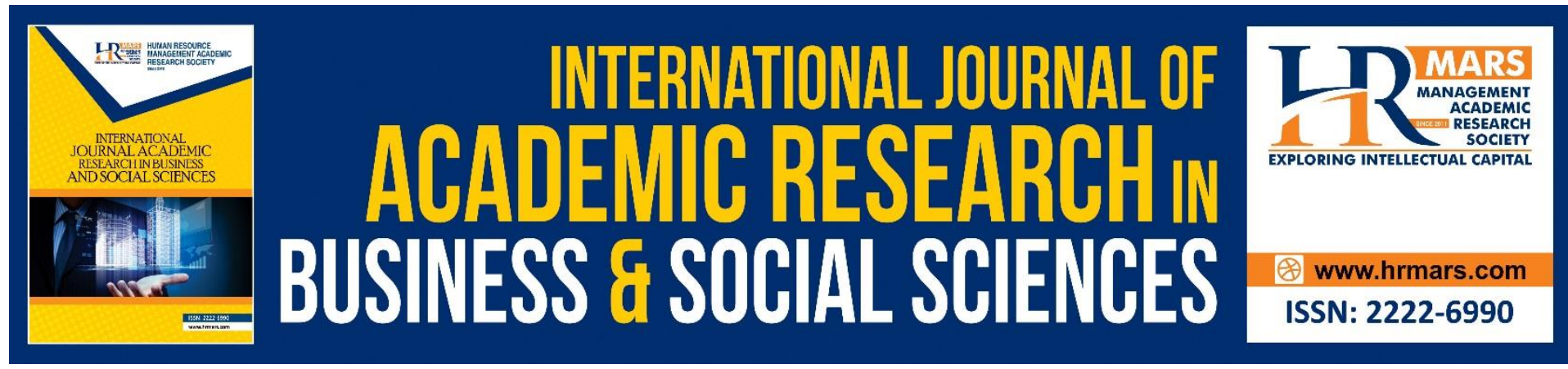

\title{
Spectral Analysis of EEG Signals during Working Memory Tasks
}

\author{
S. N. A. Naushad ${ }^{1}$ and W. Mansor ${ }^{1,2,3}$ \\ ${ }^{1}$ Faculty of Electrical Engineering, Universiti Teknologi MARA, \\ 40450 Shah Alam, Selangor Malaysia, ${ }^{2}$ Microwave Research Institute, Universiti Teknologi \\ MARA, 40450 Shah Alam, Selangor Malaysia, ${ }^{3}$ Computational Intelligence Detection RIG, \\ Health and Wellness ReNeU, Universiti Teknologi MARA, 40450 Shah Alam, Selangor \\ Malaysia
}

\begin{abstract}
Assessment of the working memory performance is important to assist in the design of an effective pedagogical technique that suits the requirements of each learner. Most researchers used bulky equipment and an invasive technique to study working memory performance. The use of non-invasive electroencephalogram (EEG) to examine the working memory status directly from the brain is very limited. This paper describes the analysis of EEG signals during working memory tasks using power spectral density to identify the suitable frequency range for examining the working memory performance. The recorded EEG signals were filtered to remove the unwanted signals. Power spectral density was computed on four frequency band signals to identify the signal strength at each location on the scalp and to examine the brain active regions. Results from the analysis showed that the low-frequency theta could reveal the working memory status for all activities. The findings in this work can be used to develop an EEG-based Working Memory Assessment system that can assist educators to strategise in helping learners to succeed academically.
\end{abstract}

Keywords: Brainwaves, Power Spectral Density, Bandpass filtering, Fast Fourier Transform, Theta Band, Alpha Band.

\section{Introduction}

Working memory is one of the predictors of academic success. It is an area in the brain where knowledge and abilities are acquired and a variety of complex cognitive tasks are performed. It enables human to recall and manipulate a limited amount of stored information in a short duration (Braddely et al., 2010). Numerous researchers have studied the working memory to find a suitable technique that can improve it. (Gao et., 2010) investigated the relation between control attention and spatial working memory. (Gillete, 2007) used computerized statistical tests to assess the working memory capacity in the self-ordered selection paradigm. According to (Alzubhi et al, 2003) the working memory can be improved using an interactive game-based learning approach.

Electroencephalogram (EEG) can be used to monitor the working memory status during the learning process. It contains a large amount of information on brain functionality, 
disorder and others. EEG signals provide several advantages; it is non-invasive and neurological activities can be recorded close to real-time. EEG signal has five frequency bands; delta $(0.5-4 \mathrm{~Hz})$, theta $(4-8 \mathrm{~Hz})$, alpha $(8-14 \mathrm{~Hz})$, beta $(14-30 \mathrm{~Hz})$ and gamma (above $30 \mathrm{~Hz})($ AboZahhad et al., 2015).

Theta and alpha bands are the common frequencies used in the study of working memory. (Moran et al., 2010) studied the working memory performance of the human brain in theta and alpha bands obtained from Magnetoencephalogram (MEG) during visual working memory retention. Dai et al (2017) analysed the theta and alpha band cortical EEG signals during working memory using statistical analysis and then characterized the topology properties of the brain functional network in the frequency bands. To the best of our knowledge, very few studies employed the non-invasive EEG to monitor the working memory status and used power spectral density (PSD) to analyse features of the EEG signals with working memory information. Tumari et al (2012) identified the working memory impairment using Wavelet transform.

This paper describes the analysis of EEG signals obtained during working memory tasks using PSD. Three types of task in the computer-based assessment were first designed before they were employed in the EEG signal acquisition.

\section{Method}

\section{A. Subject Recruitment}

There were twenty normal subjects participated in this study. All participants are a male adult and their age range is 23 to 25 years. The subjects are in good health and have normal colour vision. The objectives and procedure of the study were explained to the subjects and consent form was given to them before the EEG recording was performed.

\section{B. Computer-Based Assessment Design}

The computer-based assessment was designed to examine whether the subject can remember what they have seen. It was developed using Powerpoint. There are three tasks given to each subject, which were remembering three different objects, the scene of image and a series of letters. The total number of the questions that were asked from the tasks were fifty.

Task 1 and task 2 were developed by referring to Cognifit website. In task 1 , the game starts with three common shapes displayed on the screen as shown in Fig. 1. The objects were presented for 4 seconds (Abdullah et al., 2011). This time duration is chosen for an immediate memory test. Our memory can capture and store information in less than 1 second when viewing a pictured scene or reading a sentence (Potter, 1993). Four choices of answers were then displayed on the screen for the subject to choose as shown in Fig 2 . There were ten questions prepared for this task. 
Fig.1: A sample of question in Task 1

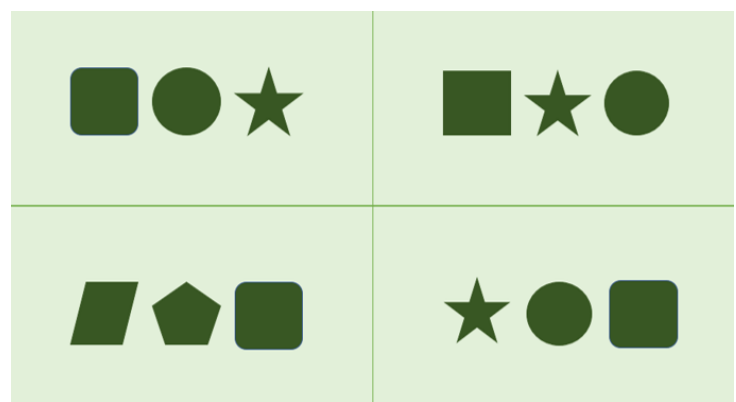

Fig. 2: A sample of answer choices

In task 2, an image of a scene was displayed on the computer screen for approximately 6 seconds for the subject (see Fig. 3). While the image is presented, the subject must try to remember the objects, their quantity and colour. After 6 seconds, the image disappeared and the subject has to answer the questions. Fig. 4 shows some of the questions that must be attempted by the subject. This task comprises five images and there were four questions for each image.

Task 3 is a series of letter memorisation which was developed based on the previous work (Onton et al., 2005) with some modifications. The long and short letters were displayed on the computer screen alternately. At the beginning of each letter, there is a fixation symbol which has to be viewed by the subject for $5 \mathrm{~s}$. Then, a series of letters were displayed in $1.4 \mathrm{~s}$ for each letter as shown in Fig. 5 . The black coloured letters need to be memorized while the green coloured should be ignored. A $2 \mathrm{~s}$ for the maintenance period was provided for the subject to rehearse the identities of the letters silently. After the maintenance period, the subject has to respond to the questions. There are twenty questions for this task.

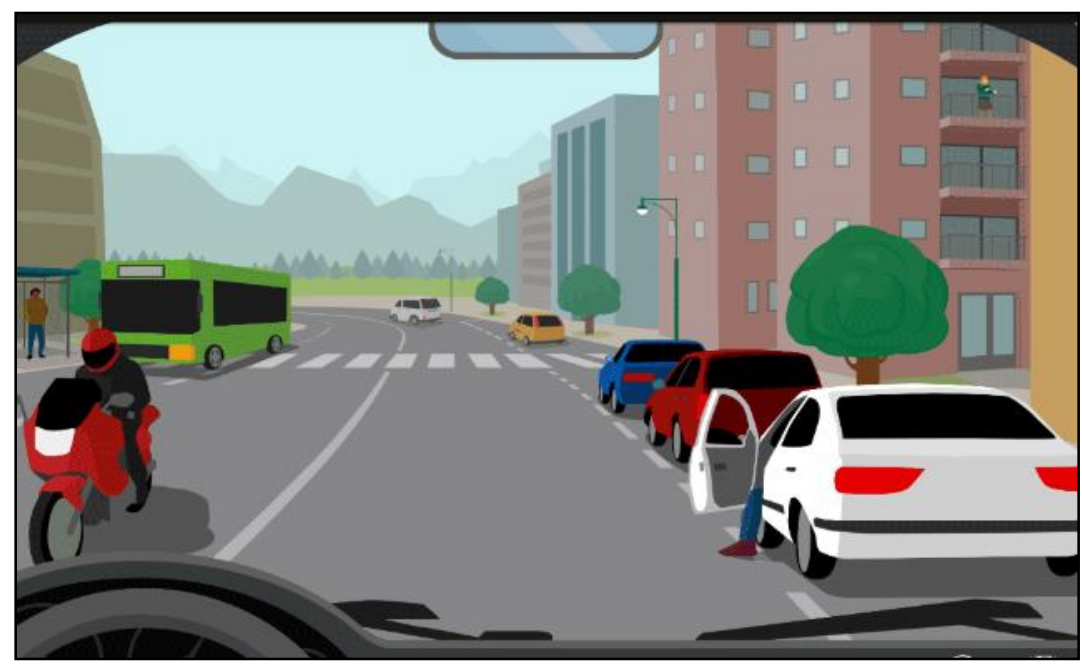


Fig. 3: A sample of image shown to the subject in Task 2

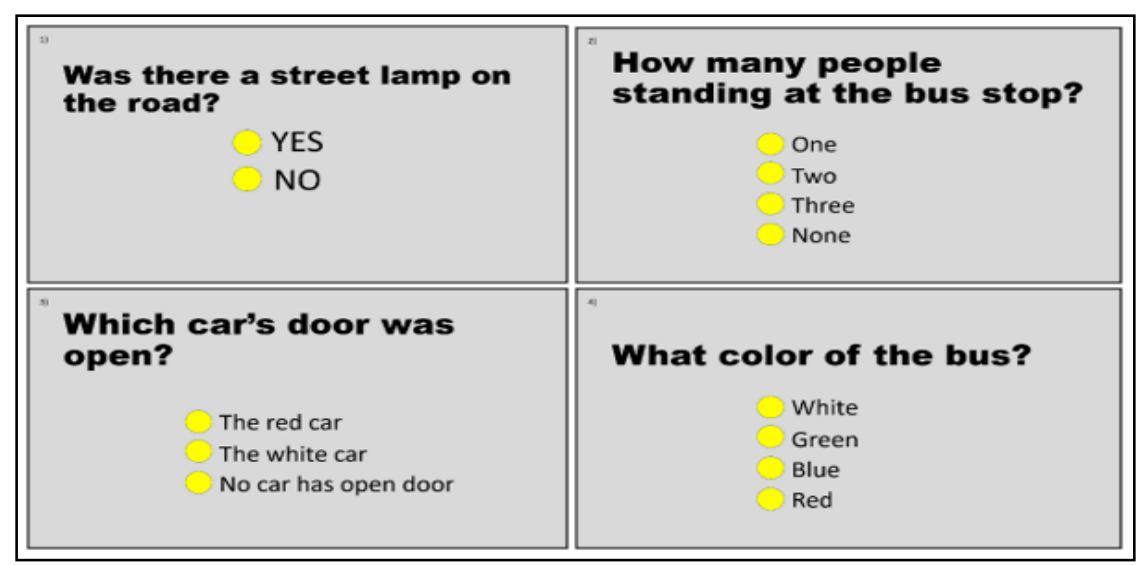

Fig. 4: Questions and answers displayed in task 2

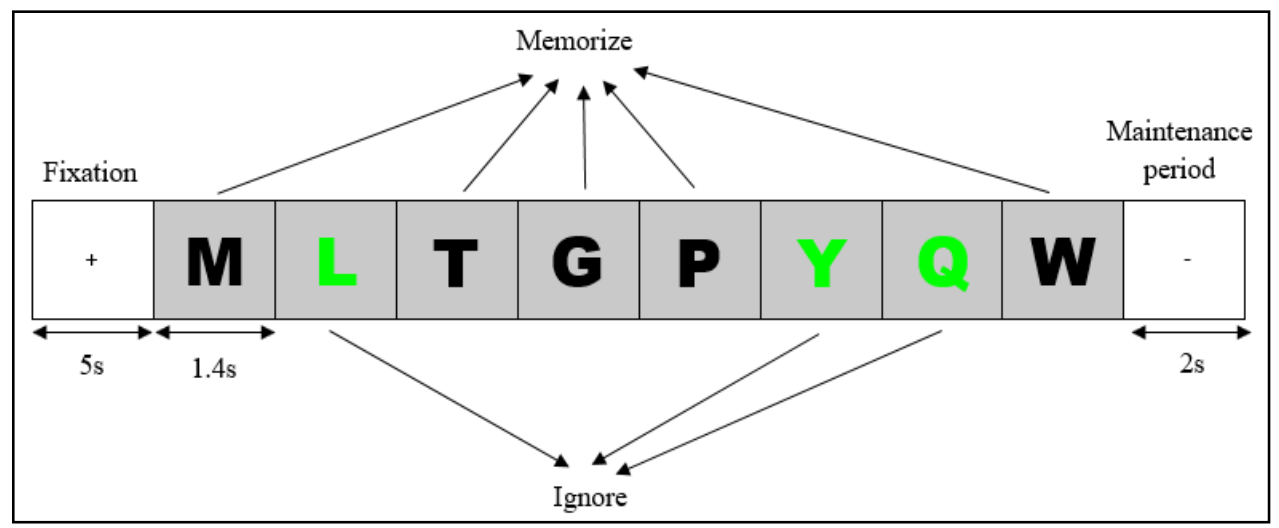

Fig. 5: A series of letters in task 3

\section{EEG Data Acquisition}

The EEG signal was acquired using Neuroelectrics Enorbio 32. Six dry electrodes were positioned on the scalp at $\mathrm{Fp} 1, \mathrm{Fz}, \mathrm{Cz}, \mathrm{Pz}, \mathrm{O} 1$, and $\mathrm{O} 2$ as shown in Fig. 6 . The ground electrode used was located at the $\mathrm{Cz}$. These electrode placements are the standard International EEG 10-20 system and related to the working memory. The location Fp1 and Fp2 are for attention, $\mathrm{Fz}$ is for working memory, $\mathrm{Pz}$ is for cognitive processing and $\mathrm{O} 1$ and $\mathrm{O} 2$ are for visual processing. The EEG signal was recorded during relaxing and performing the tasks at a sampling frequency of $500 \mathrm{~Hz}$.

Fig. 6: The locations of electrode used in the work. 
Fig. 7 shows the sequence of activities that the subject carried out during EEG recording. Initially, the subject was rest for three minutes to clear the memory from previous activities and start fresh. Then, the instructions were displayed on the laptop screen for the subject to read followed by the questions for each task. During performing the tasks, the subject has to respond by clicking the mouse using their right hand.

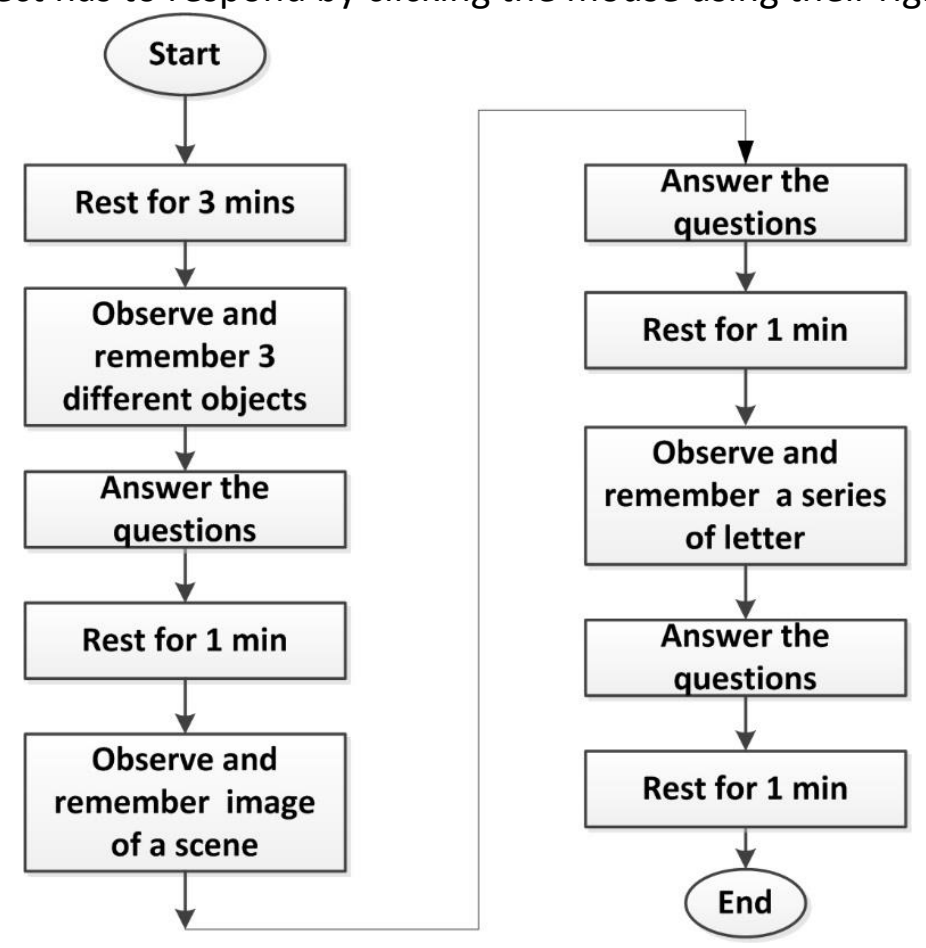

Fig. 7: The sequence of activities during EEG recording.

\section{EEG Signal Processing Analysis}

The recorded EEG signal contains interferences such as eye blinks, baseline drift, power line interference and others that have to be removed. In this study, a high pass filter with the cutoff frequency of $0.5 \mathrm{~Hz}$ was used to remove the baseline drift. Then a bandpass filter was employed to extract the signal that contains the information of working memory. The signals were filtered at four frequency ranges; $4-5 \mathrm{~Hz}, 6-7 \mathrm{~Hz}$ (Kropotov, 2019), 8-9 Hz and 10-12 Hz. The $4-7 \mathrm{~Hz}$ is a low-frequency theta which is used for capturing working memory activity (Dai et al., 2017). Fast Fourier Transform (FFT) was then computed to analyze the EEG signal using equation (1). Power Spectral Density (PSD) was performed to identify the energy and strength of the signal using equation (2), followed by the computation of the average PSD. The whole process is illustrated in Fig 8.

$X(k)=\sum_{n=0}^{N-1} x(n) \cdot W_{N}^{n k}$

where $X(k)$ is the coefficients that lie in the range of $0 \leq k \leq(N-1), x(n)$ is the signal and $W_{N}^{n k}$ is a periodic function.$$
P\left(X_{k}\right)=\frac{1}{N^{2}}\left[\left|X_{k}\right|^{2}+\left|X_{N-k}\right|^{2}\right]
$$

where $k=1,2, \ldots \ldots .\left(\frac{\mathbb{N}}{2}-1\right)$
} 


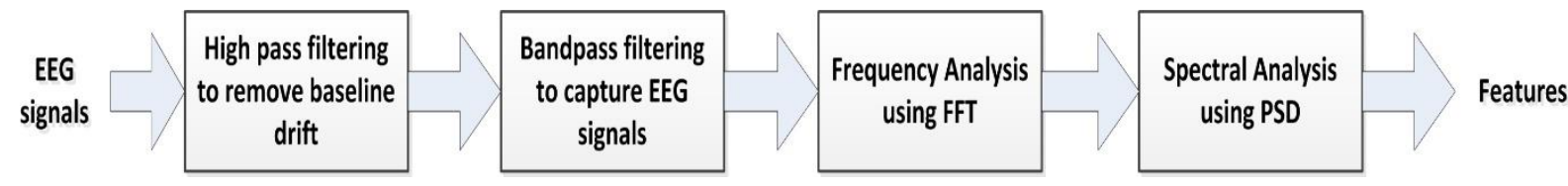

Fig. 8: Process of analyzing the EEG signal

\section{Results and Discussion}

Fig. 9 shows the power spectrum of the EEG signals of a subject obtained from channel Fz at low-frequency theta $(4-5 \mathrm{~Hz})$, higher frequency theta $(6-7 \mathrm{~Hz})$, low-frequency alpha $(8-9 \mathrm{~Hz})$ and higher frequency alpha $(10-12 \mathrm{~Hz})$ during relax. It is observed that the signal is strong at the higher alpha band (see Fig. 9(d)). This shows that the subject is in relaxing mode. For some subjects, the theta band signal strength is the highest indicating that the subjects are in deep relaxation. During working memory tasks, the signal strength is highest at low-frequency theta and the strength degrades as the frequency increases as shown in Fig. 10. The observation at low-frequency theta during working memory is in agreement with those reported by (Kropotov, 2005; Onton et al., 2010).

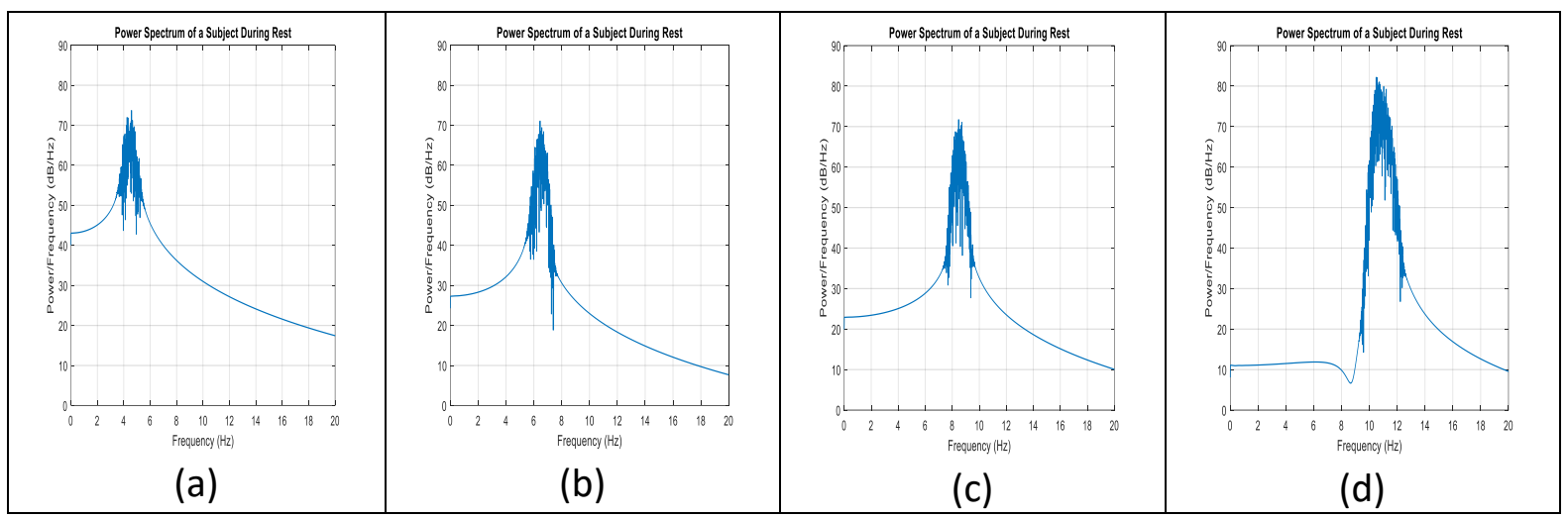

Fig. 9: PSD of EEG signal obtained during relax at (a) $4-5 \mathrm{~Hz}$ (b) $6-7 \mathrm{~Hz}$ (c) $8-9 \mathrm{~Hz}$ and (d) 10-12 $\mathrm{Hz}$ frequencies

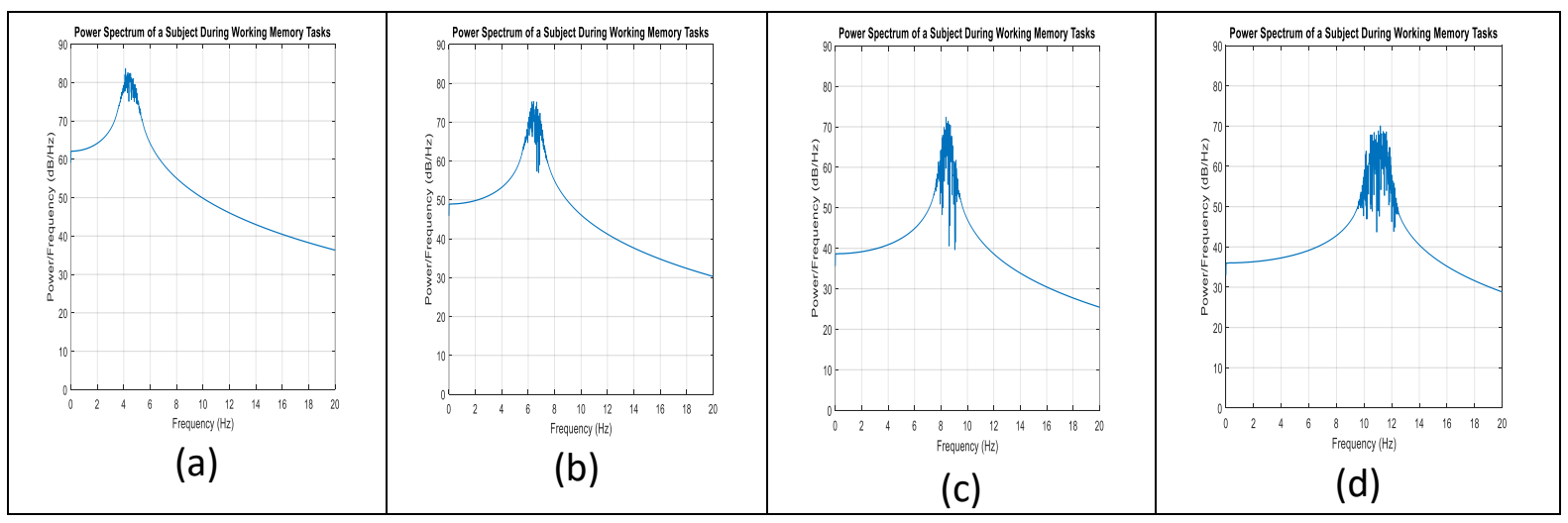

Fig. 10: PSD of EEG signal obtained during working memory task 1 at (a) 4-5Hz (b) 6-7 Hz (c) 8-9 $\mathrm{Hz}$ and (d) 10-12 Hz frequencies

Table 1 shows the average PSD for all electrode placements computed at $4-5 \mathrm{~Hz}$ during working memory tasks 1, 2 and 3. Fp1 produces the highest average PSD for all tasks which show that the subjects give full attention during the activities. Task 1 provides the highest average PSD $(79.8 \mathrm{~dB} / \mathrm{Hz})$ at $\mathrm{Fz}$ indicating that the working memory of the subjects is more 
active during task 1 compared to other tasks. There is not much difference in the strength of the EEG signals at Pz for all tasks. Based on the strength of the EEG signals at Pz, O1, O2, Fz and T7, task1 is the best task to be used in the examination of the working memory and other related brain regions performance via EEG compared to other tasks.

TABLE 1 : Average PSD Obtained during Working Memory Tasks at 4-5 Hz

\begin{tabular}{|c|c|c|c|}
\hline \multirow{2}{*}{$\begin{array}{c}\text { Electrode } \\
\text { placements }\end{array}$} & \multicolumn{3}{|c|}{ Average PSD (dB/Hz) } \\
\cline { 2 - 4 } & Task 1 & Task 2 & Task 3 \\
\hline Pz & 74.78 & 74.69 & 74.43 \\
\hline O1 & 76.71 & 76.63 & 75.89 \\
\hline O2 & 78.26 & 78.15 & 75.49 \\
\hline Fz & 79.80 & 76.80 & 78.09 \\
\hline Fp1 & 82.66 & 82.85 & 84.25 \\
\hline T7 & 77.43 & 77.35 & 75.80 \\
\hline
\end{tabular}

The findings of this study which are the suitable electrode placements and working memory tasks can be employed in the EEG-based memory assessment system. This study only used six electrode placements to observe the activity of the working memory. Even though it is sufficient, in designing the pedagogical strategies by referring to the EEG-based assessment system results, another memory types which are verbal memory and spatial memory have to be included to produce a comprehensive teaching strategy. Therefore, it is recommended that the electrode locations T3, P3 and P4 (Grigore, 2017) are employed in future research to assess the learners' memory performance.

\section{Conclusion}

The spectral analysis of EEG signals during working memory tasks of three types has been described in this paper. The EEG signals during relax and working memory tasks were divided into four frequency bands and analysed using PSD. It was found that the low-frequency theta could reveal the working memory status for all activities. Other analysis methods can be investigated in future work with the inclusion of a few more electrode placements associated with verbal memory and spatial memory.

\section{Acknowledgements}

This work was supported by LESTARI SDG, UiTM (600-RMC/LESTARI SDG-T 5/3 (129/2019). The authors would like to Research Management Centre and Faculty of Electrical Engineering, Universiti Teknologi MARA, Shah Alam, Malaysia, for financial support, facilities and various contributions.

\section{References}

Abdullah, S. Z., \& Ali, N. M. Using moving and static RSVP presentation modes on children's digital flashcard. In 2011 International Conference on User Science and Engineering (iUSEr) (pp. 95-99). IEEE.

Abo-Zahhad, M., Ahmed, S. M., \& Abbas, S. N. (2015). A new EEG acquisition protocol for biometric identification using eye blinking signals. International Journal of Intelligent Systems and Applications, 7(6), 48. 
Alzubi, T., Fernández, R., Flores, J., Duran, M., \& Cotos, J. M. (2018). Improving the working memory during early childhood education through the use of an interactive gesture game-based learning approach. IEEE Access, 6, 53998-54009.

Baddeley, A. (2003). Working memory: looking back and looking forward. Nature reviews neuroscience, 4(10), 829-839.

Dai, Z., De Souza, J., Lim, J., Ho, P. M., Chen, Y., Li, J., ... \& Sun, Y. (2017). EEG cortical connectivity analysis of working memory reveals topological reorganization in theta and alpha bands. Frontiers in human neuroscience, 11, 237.

Gao, Y., Wu, J., \& Zhang, M. (2010). Investigation on human characteristic of relationship between spatial working memory and controlled attention for education. In 2010 3rd International Conference on Biomedical Engineering and Informatics (Vol. 5, pp. $1927-$ 1931). IEEE.

Gillett, R. (2007). Assessment of working memory performance in self-ordered selection tests. Cortex, 43(8), 1047-1056.

Grigore, D. (2017). Method for Assigning and Calibrating the Psychological Indicators in MindMi Psychometric Systems. Available at SSRN 2983141.

Kropotov, J. D. (2009). Frontal Midline Theta Rhythm. Quantitative EEG, Event-Related Potentials and Neurotherapy, 77-79.

Lisman, J. E., \& Idiart, M. A. (1995). Storage of 7+/-2 short-term memories in oscillatory subcycles. Science, 267(5203), 1512-1515.

Marry Potter C. (1993). Very short-term conceptual memory. Symposium Short-term memory: Where do we stand? 32nd Annual Meeting of the Psychonomic Society, 156161.

Moran, R. J., Campo, P., Maestu, F., Reilly, R. B., Dolan, R. J., \& Strange, B. A. (2010). Peak frequency in the theta and alpha bands correlates with human working memory capacity. Frontiers in human neuroscience, 4, 200.

Onton, J., Delorme, A., \& Makeig, S. (2005). Frontal midline EEG dynamics during working memory. Neuroimage, 27(2), 341-356.

Tumari, S. M., Sudirman, R., \& Ahmad, A. H. (2012). Identification of working memory impairments in normal children using wavelet approach. In 2012 IEEE Symposium on Industrial Electronics and Applications (pp. 326-330). IEEE. 